\title{
O estranho e a concha: espaços do exílio em Adriana Lisboa
}

\section{The stranger and the shell: spaces of exile in Adriana Lisboa}

Doutora em Literatura Comparada pela UFRJ. É autora dos romances A fome de Nelson (2005), Judite no país do futuro (2008), Estranhos no aquário (2012) - premiado coma bolsa de criação
literária da Petrobras - e A feira (2017), finalista literária da Petrobras - e A feira (2017), finalista
do Prêmio Rio de literatura, e organizadora, com To Prêmio Rio de literatura, e organizadora, com da herança árabe e judaica (2010).

(ii) https://orcid. org/0000-0003-3695-9021

E-mail: adriarmony@uol.com.br
Adriana Armony

Programa de Pós-Graduação em Letras, Faculdade de Letras, Universidade Federal do Rio de Janeiro. Rio de Janeiro, RJ, Brasil.

RESUMO: Marcada pelo exílio, a obra de Adriana Lisboa, ela própria uma imigrante nos Estados Unidos, se move em espaços caracterizados pela melancolia, pelo luto - pessoal e cultural - e pelos afetos da intimidade. Este trabalho se propõe investigar como a experiência do exílio é representada espacialmente, mais especificamenteno romance Azulcorvo. Mostra-se como essa experiência se associa àfigura da concha, definida por Bachelard em Poética do espaço como uma casa que cresce na mesma medida em que cresce o corpo que a habita, numa dialética do escondido e do manifesto em que o ser mais mole constitui a concha mais dura e, ao mesmo tempo, prepara um turbilhão e uma saída. Assim também o estranho/estrangeiro produz a fortaleza da sua morada a partir da fraqueza e da morte, apontando para uma saída que, sintoma ou cura, se concretiza não tanto em espaços reais quanto no plano da imaginação.

Palavras-chave: Exílio; Espaço diaspórico; Melancolia; Adriana Lisboa.

ABSTRACT: The work of Adriana Lisboa, who is herself an immigrant in the United States, is remarkably influenced by exile. The author's narrative is characterized by the melancholy, by the mourning - personal and cultural - and by the affections of intimacy. This paper aims to investigate how the exiling experience is represented spatially, particularly in the novel Azul corvo. This experience is depicted as an association with the image of a shell. In Poetics of space, this image is defined by Bachelard as a house which grows as the body inhabiting it does the same. This simultaneous growth takes place in a dialectical movement of the "hidden" and of the "shown" in which the softest being constitutes the hardest shell and, at the same time, produces a turmoil and a way out. In this context, the stranger/foreigner builds the strength of his dwelling out of weakness and death, signalling an exit which, either symptom or cure, is accomplished not as much in actual spaces as in the level of the imagination.

Keywords: Exile; Diasporic space; Melancholia; Adriana Lisboa. 


\section{Introdução}

1 arte significativa da literatura brasileira mais recente tem se voltado para a experiência do exílio, desviando-se da tradição dos nacionalismos literários que costuma orientar a construção do cânone. Autores como Paloma Vidal, Luiz Ruffato e Adriana Lisboa traduziram essa experiência em romances como Algum lugar, Estive em Lisboa e lembrei de você e Azul corvo, protagonizados por imigrantes vivendo em um espaço impreciso entre a fronteira e a clandestinidade. Sua escrita atesta não só uma deriva, mas também um desejo: o de que a literatura brasileira amplie fronteiras e imaginários.

Libertário e fora das regras, o viajante da literatura brasileira contemporânea contrapõe-se aos seus predecessores no tempo e no espaço. Não mais o doce mundo das viagens do personagem jovem e mundano do século XIX, que sai do país para estudar e volta com ideias liberais para construir um Brasil mais europeu, como nos romances românticos em que a figura do viajante é apenas motivo de conversação e lembrança; não mais o mundo sacrificado do imigrante trabalhador do início do século XX retratado em obras que procuram inventariar a chegada desses imigrantes, fixando a imagem de um Brasil em construção com o apoio do imigrante europeu, como nos romances República dos sonhos, de Nélida Piñon e Relato de um certo Oriente, de Milton Hatoum. No século XXI, o viajante contemporâneo vaga como um flâneur na nova paisagem globalizada, entre a consciência do exílio e o contato com a clandestinidade (cf. PIRES, 2014, p.389-403).

Num mundo cada vez mais globalizado e interconectado, em que se borram os limites e fronteiras em novas combinações de espaço-tempo, subjetividades se transformam, identidades se deslocam. Já em 1998, Bhabha sugeria que histórias transnacionais de migrantes, colonizados ou refugiados políticos pudessem ser o novo terreno da literatura mundial, no lugar da transmissão das tradições nacionais (BHABHA, 1998, p.33). Nas narrativas contemporâneas, protagonistas migrantes enfrentam circunstâncias de instabilidade social e identitária, e, com frequência, o luto cultural.

Relacionada com os movimentos de migração do final do século XX, que modificaram a representação do sujeito na escrita, inscrevendo nela a voz de estrangeiros e exilados, essa nova inflexão da literatura tem sido objeto de múltiplas categorizações. Muitas delas se movem no campo semântico do espaço: conceitos como "zona de contato" (PRATT, 1999) local descontínuo em que identidades novas são produzidas em função do fluxo de pessoas - ou "espaço intersticial" (BHABHA, 1998) - definidor dos locais de hibridez e mistura de culturas distintas - destoam do ideal de homogeneidade e continuidade da tradição. A noção de entre-lugar, assinalando a representação de um novo espaço identitário, discursivo e social, tem sido especialmente produtiva. O termo surge na obra de Silviano Santiago para definir o espaço em que se move o escritor latino-americano:

entre o sacrifício e o jogo, entre a prisão e a transgressão, entre a submissão ao código e a agressão, entre a obediência e a rebelião, entre a assimilação e a expressão - ali, nesse lugar aparentemente vazio, seu templo e seu lugar de clandestinidade, ali, se realiza o ritual antropófago da literatura latino-americana (SANTIAGO, 1978, p. 26).

Em todos esses conceitos, subjaz uma oposição de base: a que distingue centro e periferia. Trata-se de uma relação não apenas espacial mas, sobretudo, geopolítica e econômica. Moretti, em "Conjecturas sobre a literatura mundial" (2000), chama a atenção para o fato de que a teoria literária tem recorrido frequentemente às metáforas econômicas: importação do romance, empréstimos diretos e indiretos, dívida externa são termos utilizados por autores como Itamar Even-Zohar e Roberto 
Schwarz ${ }^{1}$. As noções de centro e periferia, ocidental e local, provenientes do sistema-mundo da história econômica, se aplicariam ao próprio sistema literário:

em culturas que integram a periferia do sistema literário (ou seja, quase todas as culturas, dentro e fora da Europa) o romance moderno desponta não como um desenvolvimento autônomo, mas como uma conciliação entre uma influência formal ocidental (em geral francesa ou inglesa) e matérias locais (MORETTI, 2000, p. 177).

Segundo Moretti, a literatura-mundo se funda justamente nessa assimetria espacial, que, por sua vez, se expressa na própria forma literária. Com base na leitura e análise de obras literárias periféricas feitas por outros autores, numa estratégia que chama de "distant reading"2, Moretti propõe que "o sistema literário uno e desigual não é aqui uma simples rede externa, não permanece fora do texto: está bem aninhado em sua forma” (p.179). Os textos da periferia importariam, assim, formas típicas do seu local de produção e as acolheriam em suas próprias produções, num difícil processo de conciliação.

O próprio conceito de literatura-mundo - desde a sua primeira formulação, no século XIX (Weltliteratur), quando Goethe anunciava o início de uma nova era literária marcada pela diluição das fronteiras nacionais emerge a partir do momento em que a circulação e a recepção dos textos literários deixam de estar confinadas a um espaço ou uma língua. Para David Damrosh (2003), a literatura-mundo engloba todos os textos que circulam

\footnotetext{
Cf. SCHWARZ, Roberto. Ao vencedor as batatas. 5a ed. São Paulo: Duas Cidades/Ed. 34, 2000: 47 e EVEN-ZOHAR, Itamar. Laws of literary interference. In. Poetics Today, 1990, p. 54-62.

2 Segundo Moretti, no caso de uma literatura mundial "a história literária rapidamente se tornará bem diversa do que é no caso de uma literatura mundial, "a história literária rapidamente se tornará bem diversa do que é agora: se tornará de "segunda mão", uma colcha de retalhos da pesquisa de outras pessoas, sem uma unica leitura textual direta. Ainda ambiciosa, e na verdade tanto mais do que antes mais ambicioso o projeto, maior terá de ser a distância" (2000, p. 175).
}

para lá da sua cultura de origem, seja em tradução, seja na sua língua original, ou seja, sempre que uma obra literária está ativamente presente num sistema literário alheio ao da sua cultura original.

No Brasil, se Silviano Santiago descreveu esse processo de "conciliação" como "o entre-lugar da literatura latino-americana" (1978), Roberto Schwartz, no famoso ensaio de abertura do livro Ao vencedor as batatas cunhou a expressão "ideias fora do lugar" (1977) para descrever a comédia ideológica nacional representada pela disparidade entre a sociedade escravista e as ideias do liberalismo europeu. Nos dois casos, a metáfora espacial parece pressupor uma geografia relativamente fixa (centro-periferia) e um sentido de deslocamento ou inadequação (entre/ fora).

Mas Buescu (2012), em tempos em que a literatura-mundo é não apenas uma tendência mas um projeto ${ }^{3}$, vai mais longe. Afastando-se de uma concepção de literatura centrada na nação ou no uso de uma língua nacional, a autora afirma que o conceito de literatura-mundo "destaca a possibilidade de conceber diferentes mapas da produção literária, relativizando a existência de uma hierarquia pré-fixa e sublinhando um movimento de natureza mais rizomática" (BUESCU, 2012, p.48). Por outro lado, não só a obra, mas o próprio olhar sobre ela seria "descentrado": seria necessário analisar as literaturas não apenas a partir do centro/eurocentrismo, mas à luz das próprias margens, o que implica, entre outras coisas, negar a existência de um cânone único ou formas unívocas de leitura.

${ }^{3}$ Exemplar nesse sentido é o projeto "Literatura-Mundo: Perspetivas em Português", coordenado pela própria professora Helena Buescu, do Centro de Estudos Comparatistas da Faculdade de Letras da Universidade de Lisboa, em articulação com o Institute of World Literature, da Universidade de Harvard, e com o consórcio do projeto europeu, University and School for a European Canon. O projeto, Harvard, e com o consórcio do projeto europeu, University and School for a European Canon. O projeto, que conta com o selo UNESCO, é uma antologia organizada em três partes, nomeadamente: "Mundos em português" - com textos produzidos em língua portuguesa; "O mundo lido: Europa" - literatura europeias em tradução; e "Do Tejo vai-se para o mundo: o planeta" - que absorve os restantes espaços
literários não enquadrados na primeira e segunda parte. 
Poderíamos identificar, portanto, duas concepções (figuras) espaciais diversas no campo de estudo da literatura-mundo: uma que trabalha com a oposição entre centro e periferia e outra com a imagem de rizoma ou rede.

Se nos voltarmos para a noção de sujeito, veremos essas concepções reaparecerem nas figuras de sujeito migrante e sujeito transnacional. Paterson, em "O sujeito em movimento: pós-moderno, migrante e transnacional" (2015), afirma que enquanto o sujeito migrante funda sua identidade no duplo ("eu sou Outro"), na distância ("Eu sou estrangeiro") e na perda de posse identitária ("Eu sou exilada"), o sujeito transnacional (conceito inspirado pelos trabalhos de Homi Bhabha e de Gayatra Spivak) implica um processo segundo o qual formações identitárias tradicionalmente circunscritas por fronteiras políticas e geográficas ultrapassam fronteiras nacionais para produzir novas formações de identidade. Há um distanciamento do discurso identitário estrito em proveito da pulverização, da heterogeneidade e do movimento, recusando-se as definições identitárias estanques:

Diferentemente do sujeito migrante, o transnacional rejeita a noção de uma identidade formada a partir dos critérios de raça ou de local de origem em proveito de uma identidade complexa, mutável, frequentemente multicultural e exterior ao recinto das lembranças. (...) A relação com o espaço é um "aqui e agora" e de "presença no mundo", confirmada pela rejeição à nostalgia e pela alegria manifesta da viagem (PATERSON, 2015, p.182-183).

Na obra de Adriana Lisboa, ela própria uma imigrante nos Estados Unidos, a experiência do desenraizamento e a fluidez identitária aparecem de forma recorrente. Neste artigo, procuraremos acompanhar a traduçã $o^{4}$

\footnotetext{
${ }^{4}$ Cf. DERRIDA: "nos limites em que ela [a tradução] é possível ou pelo menos parece possível, a tradução pratica a diferença entre significado e significante. Mas se essa diferença nunca é pura, a tradução não o é menos, e será preciso substituir a noção de tradução pela noção de transformação, de transformação regulada de uma língua por outra, de um texto por outro" (Positions, Paris, 1972).
}

dessa experiência em três de seus romances: Azul Corvo, que se passa no Colorado, EUA; Hanói, que tem Chicago como cenário e cujos protagonistas são um filho de imigrante mexicano e uma descendente de vietnamitas; e Rakushisha, situado no Japão.

Nossa hipótese é que, em Adriana Lisboa, o desenraizamento do exílio se transfigura no "talento para viajar", conforme enunciado em seu romance Rakushisha (LISBOA, 2007, p.11). A viagem éentão ponto de partida para a criação de novos espaços, marcados pela melancolia e pelo luto - pessoal e cultural -, mas também pela proliferação poética. Essa experiência de exílio é cheia de nuances, e se desdobra em estranhamento, pesadelo, promessa.

\section{Estranhamento}

A etimologia de "estrangeiro" indica que o imigrante é, inerentemente, um estranho. Ambas as palavras derivam do latim extraneus, "o que é de fora", de extra, "fora" (HOUAISS, Dicionário eletrônico de língua portuguesa). Em três de seus romances, Adriana Lisboa narra experiências de exílio e estranhamento. Em Azul corvo, a protagonista é Evangelina, uma menina de treze anos que, após a morte da mãe, viaja de Copacabana ao Colorado, nos Estados Unidos, em busca de seu verdadeiro pai, de quem sabe apenas que é norte-americano e pode estar em qualquer lugar do mundo. Ao deixar o Rio de Janeiro para morar em Lakewood com seu padrasto, o exguerrilheiro Fernando, Vanja se vê na interseção entre dois mundos, sem pertencer exatamente a nenhum deles. Em Hanói, Alex e David são filhos de imigrantes, vivendo num mosaico de hábitos, culturas e identidades flutuantes. Enquanto Alex é mãe solteira e procura conciliar os estudos ao trabalho no mercado asiático, David, um trompetista apaixonado por jazz, foi diagnosticado com uma doença terminal, o que acentua os sentimentos de deslocamento e transitoriedade. Em Rakushisha, Haruki é 
um desenhista carioca de origem nipônica que, contratado para ilustrar a tradução de uma clássica obra japonesa, resolve passar um tempo no país de seus antepassados e, num gesto impensado, convida Celina, uma mulher enigmática que acabara de conhecer num vagão de metrô do Rio de Janeiro, a acompanhá-lo em sua viagem.

Nos três romances, o exílio aparece associado à experiência da morte. Em Hanói, o motor do enredo é a doença terminal do filho de imigrantes David; em Azul corvo, o exílio de Vanja é motivado pela morte da mãe; em Hakushisha, Celina, na viagem ao Japão, é assombrada pela lembrança da filha morta em um acidente sete anos antes. Esses três personagens centrais se movem no campo do estranho. Vanja sai do calor familiar de Copacabana para o cenário inóspito do Colorado; Celina perambula pelo Japão, esse absolutamente outro, com suas imagens hipnóticas de neon; David vê o estranhamento se imiscuir no próprio corpo na forma de um câncer, que o conduz progressivamente ao esquecimento, e sua casa se esvazia em paralelo à sua memória. O exílio é o espaço do estranho - e a morte, o estranhamento absoluto.

Também em Azul corvo o estranho se traduz numa economia da ausência. Já na abertura da narrativa, tempo e espaço são representados como um deserto: "Ter treze anos é como estar no meio de lugar nenhum. O que se acentuava devido ao fato de eu estar no meio de lugar nenhum" (LISBOA, 2014, p.16), diz a narradora Vanja. Casa, cidade, país, a família de um homem só: nada disso era seu.

A narradora inicia sua representação do espaço do exílio pelas baratas: em Copacabana, "estavam em toda parte", enquanto no Colorado, "lugar estranho", "seco" de "ar duro", "de pedra”, um lugar que "não era feito para os seres humanos", nunca via baratas (ou eram "bem mais discretas") (LISBOA, 2014, p.15-16). Umidade versus secura, profusão versus ausência: essa oposição inaugural reaparece em vários outros pontos do romance.
As imagens do deserto se multiplicam. A amplidão do Colorado se opõe aos espaços confinados do Rio de Janeiro. Na cidade semiárida, as ruas eram "largas e limpas e sem sombra", "o céu se esticando", com "o chão plano acima de você", enquanto Copacabana tem "ruas estreitas e sujas" e "calçadas esbugalhadas com telhados de árvores presentes o ano inteiro" (LISBOA, 2014, p.24-25). Instala-se uma ditadura do espaço. "Uma infinidade de chão para a direita, uma infinidade de montanhas para a esquerda"; "plana, lisa, tediosa, poeirenta, uniforme, contínua, constante, chata, sem graça" (LISBOA, 2014, p. 30): assim as palavras povoam este deserto. A solidão é imposta pela própria amplidão espacial. Ao contrário, na Copacabana da memória, onde a mãe de Vanja continua viva, é "sempre verão, um verão irmão da água": um mundo feito de "areia, pombos, lixo, um gosto vago de picolé de fruta misturado com areia e água do mar" (LISBOA, 2014, p. 38)

A própria palavra "corvo" contém uma ambiguidade, quando confrontada com o seu correspondente em inglês. Na língua do país de destino, corvo pode ser crow (pássaro preto, onívoro e amigo do lixo, encontrado em espaços abertos, com árvores próximas e em espaços urbanos) ou raven ("indivíduo arredio e meditativo que você encontra no deserto, na tundra, nas planícies, nas florestas, nos grandes espaços abertos e mais ou menos desocupados. Preferem a solidão", diz Vanja) (LISBOA, 2014, p. 180-181).

Mas há em Azul corvo um outro exílio que precede o de Vanja: o do próprio Fernando, ou Chico Ferradura, o ex-guerrilheiro que emprestou seu nome à certidão de nascimento da filha da ex-mulher. Paradoxalmente, é junto a esse desterrado - esse quase-pai no exílio - que Vanja procura sua casa. Esse exílio também se associa ao deserto: Fernando vive em solidão, como o segurança de uma biblioteca, sem maiores objetivos que não o conforto da sobrevivência. Fernando é representante dessa diáspora contemporânea que Silviano Santiago denominou de "cosmopolitismo do pobre", resultado da dispersão anárquica de indivíduos ou grupos de familiares provenientes 
de uma região pobre ou de uma nação conturbada para as metrópoles mais endinheiradas do mundo ocidental (SANTIAGO, 2004).

Diferente do multiculturalismo do passado, em que a construção do Estado "teve como visada prioritária o engrandecimento do estadonação pela perda da memória individual do marginalizado e em favor da artificialidade da memória coletiva" (SANTIAGO, 2004, p.58), o novo multiculturalismo se fundamentaria na compreensão de um duplo processo em marcha avassaladora na economia globalizada: a desnacionalização do espaço urbano e a desnacionalização da política. O resgate dos grupos étnicos e sociais, marginalizados historicamente - os índios, as mulheres, os negros - se daria, nos novos tempos, através da implantação de um novo multiculturalismo em que não se deveria buscar a homogeneização das partes, mas a convivência e o diálogo entre as diferenças.

Na literatura brasileira, o velho multiculturalismo se manifestou ao longo dos tempos como "multiculturalismo cordial": de Iracema (1865) a Gabriela cravo e canela (1958), várias e diferentes etnias e culturas nacionais se cruzam patriarcal e fraternalmente, sob o império das elites governamentais e empresariais (cf. SANTIAGO, 2004, p.55). O novo multiculturalismo, tal como proposto por Silviano Santiago, porém, parece ter sucumbido à violência de um mundo globalizado repleto de falsas promessas, e hoje soa como uma miragem no deserto.

É essa imagem de deserto que perpassa não apenas a paisagem, mas o próprio enredo de Azul corvo. A associação entre exílio e deserto ganha um novo matiz ao ser expressa sob a forma do verbo "desertar", quando Vanja imagina o que Fernando sentiu antes e depois de "desertar dessas mulheres ou ao ser desertado por elas (desertar: tornar deserto, abandonar, despovoar; deixar de estar presente; desistir, renunciar)" (LISBOA, 2014, p. 294). Pois Fernando é um desertor: ao perceber o iminente fracasso da guerrilha do Araguaia, ele abandona sua companheira Manoela. O corvo do título assume aí um terceiro sentido: os corvos da ditadura. O deserto contém, então, outras formas de pesadelo.

\section{Pesadelo: luto e melancolia}

O Araguaia apresenta características espaciais análogas às do exílio: "o Pará é um país inteiro", uma "imensidão ao norte do Brasil", a "Amazônia brava e sobre-humana", deserto enlameado e escorregadio, "pedaço de lugar nenhum" (LISBOA 2014, p. 63-64).

Ao sair de casa para estudar técnicas de guerrilha em Pequim e em seguida se mudar para a base guerrilheira da Faveira, Fernando/Chico Ferradura já não lembrava mais o caminho de casa. "Não é que a casa estivesse em toda parte; a casa não estava em parte alguma” (LISBOA, 2014, p. 99).

A própria história passada de Fernando, em Azul Corvo, parece estranha ao movimento do romance: as narrativas do Araguaia destoam do estilo predominante, soam deslocadas, como trechos transplantados no movimento do texto principal.

Diferentemente do exílio de Vanja, o de Fernando / Chico é forçado; pior, é fruto de uma fuga que ele mesmo caracteriza como "vergonhosa".

Mas ele continuou parado, por um tempo que era uma estrada de asfalto roto cortando sua vida de leste a oeste. Do Atlântico até a fronteira do estado do Acre com o Peru. E quanto mais tempo ele continuava parado, Chico sabia, com mais força selava uma decisão imprevista e, lá dentro de seu estômago, mais vergonhosa do que a vergonhosa incompetência dos militares para acabar com aquele grupo que, por A mais B, já devia ter sido dizimado havia muito tempo. Eles, os guerrilheiros, eram fantasmas andando no meio da mata, acreditando (acreditando?) no outro mundo. Eles já eram fantasmas (LISBOA, 2014, p. 248).

O exílio ganha, então, tintas de pesadelo: espaço de fantasmas, pessoas tortas, viradas do avesso, feito cães escorraçados. Diz Vanja: 
Olho para os meus braços sem cicatrizes e penso cortes e penso choques elétricos. E me pergunto como as vidas viradas ao avesso e as pessoas viradas ao avesso reencontram o seu direito.

Não reencontram. Ficam primas da árvore que nasceu no barranco, o tronco torto para sempre e as folhas se espichando crédulas ao sol porque é isso que as folhas fazem. Ficam primas do cão escorraçado que come o prato que um dia resolvem lhe dar porque é isso que os cães fazem (LISBOA, 2014, p.156)

Chico/Fernando é aquele que vai para o exílio, não só da sua casa, mas de si mesmo: "Mateiro habilidoso que era, encontrou seu caminho para fora dali, para longe dali, para longe de tudo, de si mesmo inclusive". Este, o maior deserto, o original: o deserto de si mesmo.

Você acorda um dia e tem cinquenta anos de idade e já perdeu a vontade de fazer coisas, de andar por aí, de procurar um lugar no mundo porque a verdade é que o mundo é uma porra de um lugar selvagem do cacete. Não vale a pena. Não faz diferença (LISBOA 2014, 107).

Poderíamos chamar a este deserto: melancolia.

Há uma diferença entre luto e melancolia. Segundo Freud, o luto é a reação ao sentimento de perda de um objeto amado (que pode ser também uma abstração que ocupou o lugar de um ente querido, como o país, a liberdade ou um ideal) e não implica condição patológica desde que seja superado após certo período de tempo. Já na melancolia o objeto nem sempre é algo definido; no melancólico não se pode identificar exatamente o conteúdo da perda. Os traços mentais distintivos da melancolia são um desânimo profundamente penoso, a cessação de interesse pelo mundo externo, a perda da capacidade de amar, a inibição de toda e qualquer atividade. Sem direcionamento, a libido desloca-se para o ego estabelecendo uma espécie de identificação deste com o ente perdido. A perda objetal passa a ser uma perda do próprio ego (cf. FREUD, 2011).
Assim também a figura do imigrante: comumente associado à melancolia nas sociedades ocidentais, ele é visto como uma ferida, uma dor na sociedade na sua incapacidade de mostrar-se feliz. Nessa percepção, o racismo aparece como uma justificativa para a sua infelicidade, uma história da qual não consegue se desvencilhar ou superar. 0 migrante melancólico seria, na formulação de Sarah Ahmed, uma figura fantasmagórica que "não se apega simplesmente à diferença, àquilo que o mantém à parte, mas também à infelicidade da diferença como um itinerário histórico" (AHMED, 2010, p. 148).

Nessa mesma direção, Júlia Braga Neves, em "Um sentido para um fim: espaços migratórios e melancolia em Hanói” (2015), apontou o caráter melancólico das obras de Adriana Lisboa. Nos três romances aqui citados, de fato, a melancolia se entrelaça com a própria condição do imigrante. Em Hanói, o câncer de David funciona como a própria metáfora da multiplicação do estranho e da perda da identidade; alienado em sua condição de segunda geração imigrante, o músico vai se esvaziando progressivamente de memórias e objetos, até desaparecer no romance (e sequer podemos ler sua morte). Poderíamos pensar nessa melancolia como o fracasso de um luto cultural por parte do imigrante. De forma semelhante, Chico/Fernando perde amor e ideais: Manoela, a companheira no Araguaia; Suzana, mãe de Vanja; a revolução. Se as abandona ou é abandonado por elas pouco faz diferença: ele é esta "figura fantasmagórica", a diferença, imóvel, fechada em si mesma:

Imóvel, como um imóvel, uma casa, algo que você não arranca do chão e leva por aí, no bolso, na mala, na mochila. Uma estrutura construída sobre a terra, pesada, vedada, protegida das intempéries, preparada para o frio extremo e para o calor extremo, capaz de fechar portas e janelas ao vento, capaz de fechar cortinas aos olhos dos passantes (LISBOA, 2014, p. 242).

É contra essa imobilidade da melancolia que se voltaa crítica feita por Júlia Braga Neves. Segundo a autora, a melancolia seria paralisante (Chico é, de fato, "aquele que para", que permanece parado), enquanto a literatura 
teria, nas palavras de Judith Butler por ela citadas, "o comprometimento ético de criticar as formas vigentes de poder" (NEVES, 2015, p. 145). De acordo com Neves, ao utilizar a história pessoal dos protagonistas, suas emoções e sentimentos como síntese de uma história coletiva e forma de refletir a situação do migrante numa metrópole nos Estados Unidos, a literatura de Adriana Lisboa apresentaria limitações éticas:

ao utilizar a melancolia e a solidão como principais características dos protagonistas, Lisboa cria um debate problemático das consequências e efeitos do racismo no dia a dia, pois ela reforça a figura do migrante melancólico e enfatiza a falta de agência do migrante que é indiferente (e ignorante) às relações racistas que o rodeiam. (...) Por trás das representações de diversidade cultural pretendidas por Lisboa, percebe-se o silêncio e a inabilidade de encarar o racismo e a pobreza, problemas que também caracterizam a própria classe média brasileira (NEVES, 2015, p.155).

A autora parece não dar atenção suficiente, porém, às nuances da citação de Butler, que propõe que

o nosso comprometimento ético não pode partir do pressuposto da abjeção ou rejeição, mas de uma postura crítica em abrir possibilidades para que o desconhecido, o estranho e os modos de saber não autorizados sejam introduzidos no campo discursivo (apud NEVES, 2015, p.145).

Nesse sentido, poderíamos pensar se não haveria um valor positivo da melancolia: uma ética melancólica, aquela que justamente introduz o desconhecido e o estranho no discurso, como diz a narradora de Rakushisha:

Gosto dessa familiaridade da estranheza, de que de repente me dou conta. Gosto de me sentir assim alheada, alguém que não pertence, que não entende, que não fala. De ocupar um lugar que parece não existir. Como se eu não fosse de carne e osso, mas só uma impressão, mas só um sonho, como se eu fosse feita de flores e papéis e um tsuru de origami e o eco do salto de uma rã dentro de um velho poço ou o eco dos saltos de uma mulher na calçada e as evocações de Sei Shōnagon e de Bashō, séculos depois. Qual é o lugar que eu ocupo no mundo? Tem nome, esse lugar? Tem dimensões? Altura, largura, profundidade? Será um som, apenas, ou um gesto, ou um cheiro, ou uma possibilidade nunca explorada? 0 contrário do som. 0 contrário de um gesto - imobilidade, potencialidade. Desistência? (LISBOA, 2007, p. 127).

Por outro lado, nem sempre se trata exatamente de melancolia. As trajetórias de Vanja, em Azul corvo, de Celeste, em Rakushisha, e de Alex, em Hanói, parecem se aproximar mais do luto. Vanja perde a mãe, mas de alguma forma supera o luto ao ganhar (inventar) um pai; Celeste, ao chegar à Casa dos Caquis caídos no final de Rakushisha, consegue enfim chorar, transfigurando sua dor em poesia; Alex cumpre o desejo de David ao viajar para Hanói, onde não mais é uma imigrante melancólica, mas uma "viajante por esporte" que consegue reverter a falsidade do sorriso que marcava sua vida nos Estados Unidos.

Pois existe algo de intermediário nos desertos. Mais de uma vez, a narradora de Azul corvo os caracteriza como "caminhos apenas", "lugares entre parênteses". A própria diferença cultural pode ser vista como um deserto, já que é apenas uma passagem: “Quando Nick me beijou, eu quase perguntei que gosto tinha um beijo da América do Sul. Mas essa era uma pergunta deserta. Era uma pergunta de passagem, na qual eu optava por não residir" (LISBOA, 2014, p. 296).

É que, se "Viajar é pela viagem em si. É para ter o caminho debaixo dos pés” (LISBOA, 2007, p.120), o deserto pode ser também uma promessa.

\section{Promessa}

Copacabana não é apenas o espaço da cidade povoada e confusa. Da praia, a menina Evangelina contempla o espaço do horizonte, onde ilhas se destacam. O horizonte é abstrato, bom para “aqueles que almejam o 
impossível", enquanto Vanja prefere as ilhas: "eu preferia pensar nas ilhas e nos peixes" (LISBOA, 2014, p. 39). O mundo submarino - dos peixes, das algas, dos moluscos, das conchas azul-corvo - desconhece por completo o caos assimilado do bairro de Copacabana: "o drama da cidade não era nenhum dado no subconsciente do fundo do mar" (LISBOA, 2014, p. 40).

De forma algo misteriosa, o título do livro - azulcorvo - conduz ao deserto do Colorado: "Enquanto isso, os moluscos do mar de Copacabana silenciavam o mundo dentro de suas conchas azul-corvo. E os corvos sobrevoavam a cidade de Lakewood, Colorado. Os corvos azul-concha" (LISBOA, 2014, p.55). Entramos aqui no mundo das imagens submarinas. O mundo do poema The Fish, de Mariana Moore, que fascina a adolescente Vanja nas aulas de inglês, com seus "caranguejos como lírios verdes e chapéus de sapo submarinos. E um oceano turquesa de corpos. E as conchas azul corvo." Sun Split likespun: Sol repuxado (fendido, rachado) como vidro repuxado (LISBOA, 2014, p. 125-126).

Aqui, a experiência do exílio se associa à figura da concha, definida por Bachelard em Poética do espaço como "uma casa que cresce na mesma medida em que cresce o corpo que a habita", numa dialética do escondido e do manifesto em que "o ser mais mole constitui a concha mais dura" (BACHELARD, 1978, p. 91) e, ao mesmo tempo, prepara um turbilhão e uma saída. Diz Bachelard:

isso é verdade em toda escala de metáforas, desde a ressurreição de um ser enterrado até a expressão súbita de um homem taciturno durante muito tempo; (...) ao conservar-se na imobilidade de sua concha, o ser prepara explosões temporais do ser, turbilhões do ser" (BACHELARD, 1978, p. 87).

Vanja parece consciente dessa promessa:

Era o tempo de eu me remodelar, quem sabe eu também tinha (devia ter) aquele interior mole e albino de inseto entre um e outro esqueletos externos. Era preciso pegar aquela gosma e, depois de ter conseguido protegê-la da fulminante piedade alheia, moldá-la agora em algum formato com o qual eu me reidentificasse (LISBOA, 2014, p. 104-105).

Trata-se aqui não só de uma reflexão sobre os espaços transnacionais em que se move o estrangeiro e uma possível ideia de origem, mas também sobre o conceito de literatura. O próprio impulso narrativo (a própria literatura?) está ligado intrinsecamente a esse movimento afim ao luto e à melancolia: a tentativa de recompor uma origem perdida através de rastros e ruínas, um modo de lidar com a inevitável e grande perda de um objeto denominado o tempo passado, transportando-o imaginariamente para o presente. Na literatura brasileira, como em outros sistemas literários que procuraram afirmar sua nacionalidade, a ideia de origem tem sido frequentemente, desde o Romantismo, uma obsessão. Essa origem, porém, ao mesmo tempo que é perseguida, escapa. Como afirma Paloma Vidal, no artigo "E a origem sempre se perde": narrativa, escrita e exílio se aproximam pela necessidade de deslocamento espacial e temporal; para narrar, é preciso uma matéria trazida de territórios, tempos e tradições distantes, mas ainda, um desejo pelo sopro primitivo, mesmo que a origem pareça sempre se perder (VIDAL, 2016, p. 40).

No final de Azul corvo, Vanja reinventa a sua origem naquilo que sonha mudar: ela termina sua narrativa propondo uma nova versão do momento em que Fernando, a pedido da mãe de Vanja, vai “batizá-la”, assumindo uma paternidade que não é sua. Nessa reescrita, Fernando, ao contrário de ir embora, fica:

Ele e minha mãe se abraçaram com a força da falta que sentiam um do outro. Ele foi para a cama com ela. Mais tarde, no meio da madrugada, ela preparou uma sopa e os dois se sentaram diante da árvore de Natal para tomar a sopa.

Era para ser definitivo. E foi. (LISBOA, 2014, p. 298). 
Enquanto no passado reescrito Fernando fica, no plano da realidade presente, quem fica é Vanja. A narradora permanece na casa do padrasto depois da morte dele, e é ela que providencia o enterro desse desterrado:

Faz pouco mais de um ano que enterrei Fernando. Ele morreu sem guerrilhas, sem esposas nem amantes. Na sua memória deslizavam rios como o Araguaia e o Tâmisa e os rios encachoeirados das montanhas do Colorado, e o Rio Grande, que atravessa Albuquerque. Mas as águas dos rios encontram seu caminho até o mar, e aquilo que era doce torna-se salgado e povoado por bichos marinhos e suas conchas (LISBOA, 2014, p. 293-294).

Assim também o estranho/estrangeiro produz a fortaleza da sua morada (sua concha) a partir da fraqueza e da morte, apontando para uma saída que, sintoma ou cura, se concretiza não tanto em espaços reais quanto no plano minucioso da imaginação. Se o caminho do exílio tem duas pontas e a origem sempre se perde, resta traduzir o luto e o desejo na promessa de uma escrita. Escrita que eu gostaria de caracterizar de "luminosa", como neste trecho de Rakushisha: "E os estilhaços dessa frase luminosa ganharam o espaço, decompostos, a fim de se transformar em outra coisa, já que nada, absolutamente nada, se perde, já que tudo engendra tudo mais" (LISBOA, 2007, p. 128).

\section{Conclusão}

Os três romances de Adriana Lisboa aqui citados expressam, cada um a seu modo, questões complexas sobre exílios e migrâncias. Neste artigo, procurei fazer uma leitura mais cerrada (close reading) de um desses romances tomando como fio condutor a ideia de espaço, tão produtiva no campo da teoria literária contemporânea. A leitura convergiu para uma figura poética específica, a da concha, que compreende ao mesmo tempo uma fraqueza e uma força, um recolhimento e um renascimento.

Como afirmou Moretti (2000), esse tipo de leitura não é incompatível com a distant reading; ao contrário, uma se alimenta da outra. Gostaria, portanto, de apontar brevemente, a partir dessa leitura, alguns vetores ou interrogações (tropos, temas, problemas) para a abordagem da literaturamundo.

Em primeiro lugar, uma armadilha ou um perigo: até que ponto a ideia de transnacionalismo é utópica ou suspeita na medida em que encoraja uma denegação dos critérios de raça, de nacionalidade e de cultura? 0 triunfalismo pós-moderno não se mostrou enganoso em um mundo que permanece extremamente desigual, marcado cada vez mais pelo fechamento de fronteiras, pela xenofobia e processos de exclusão? Júlia Braga Neves, em sua crítica (2015), não estaria revelando justamente esse mal-estar?

Em segundo lugar, uma questão político-estratégica: qual seria o alcance da literatura (das literaturas) nesse contexto? Fragmentado e móvel, o sujeito contemporâneo se escreve e se inscreve em um vasto espaço literário em vias de mudança e de transformação. A literatura atual, que revela uma grande variedade de construções identitárias, desconstruindo as grandes metanarrativas e valorizando a diversidade e a heterogeneidade, é um campo de disputa em que se procura continuamente questionar, deslocar ou reinventar o cânone. Nesse sentido, "a saída" não estaria, como proposto no âmbito do pessoal e do subjetivo nos textos de Adriana Lisboa, no plano da imaginação, ou do imaginário? Não é nesse plano que as lutas se travam de forma mais radical?

Por fim, uma proposta genealógica. Gostaria de retomar a ideia de rizoma, lembrando que a palavra provém do étimo de "raiz". Para Deleuze, rizoma é uma raiz que tem um crescimento diferenciado, polimorfo, que cresce horizontalmente, sem uma direção clara e definida, caminhos 
próprios que se organizam através da contingência e da associação de elementos (DELEUZE, 2010). É curioso que o autor não use a imagem da "rede", preferindo a referência à raiz, palavra que costuma estar associada a uma ideia de origem. Talvez essa imagem seja uma pista (uma promessa) de como a origem (identidade) pode conter, promover e alimentar a multiplicidade e a transformação.

\section{Referências}

AHMED, Sarah. The promise of happiness. Londres: Duke University Press, 2010.

BACHELARD, Gaston. A poética do espaço. Tradução Antônio da Costa Leal e Lídia do Valle Santos Leal São Paulo: Abril Cultural, 1978. (Coleção Os Pensadores).

BHABHA, Homi K. O local da cultura. Tradução Myriam Ávila et al. Belo Horizonte: UFMG, 1998.

BUESCU, Helena. Mundos em Português. Vol. 1 e 2 de Literatura-Mundo Comparada: Perspectivas em Português. Lisboa: Tinta-da-China, 2017.

BUESCU, Helena. World Literature: a Reinvention of Reading. Letteratura e Letterature, v. 11, p. 51-58, 2017.

BUTLER, Judith. Parting ways: jewishness and the critique of zionism. Nova York: Columbia University Press, 2012.

DAMROSCH, David. What is world literature? Princeton and Oxford: Princeton University Press, 2003.

DELEUZE, Gilles; GUATTARI, Felix. Mil Platôs. São Paulo: Editora 34, 2010.

FREUD, Sigmund. Luto e melancolia. Tradução Marilene Carone. São Paulo: Cosac Naify, 2011.

LISBOA, Adriana. Rakushisha. 2. ed. Rio de Janeiro: Alfaguara, 2007.

LISBOA, Adriana. Hanói. Rio de Janeiro: Alfaguara, 2013.

LISBOA, Adriana. Azul corvo. 2. ed. Rio de Janeiro: Alfaguara, 2014.

MORETTI, Franco. Conjecturas sobre a literatura mundial. Tradução José Marcos Macedo. In: Novos Estudos CEBRAP, n. 58, p.173-181, nov. 2000.
NEVES, Júlia Braga. Um sentido para um fim: espaços migratórios e melancolia em Hanói, de Adriana Lisboa. Estudos de Literatura Brasileira Contemporânea, n. 45 p. 139-157, 2015.

SANTIAGO, Silviano. O entre-lugar do discurso latino-americano. In: Uma literatura nos trópicos: ensaios sobre dependência cultural. São Paulo: Perspectiva, Secretaria da Cultura, Ciência e Tecnologia do Estado de São Paulo, 1978.

SANTIAGO, Silviano. O cosmopolitismo do pobre. Belo Horizonte: UFMG, 2004

SCHWARTZ, Roberto. As ideias fora do lugar. In: Ao vencedor as batatas. São Paulo: Duas Cidades, 1977.

PATERSON, Janet. O sujeito em movimento: pós-moderno, migrante e transnacional. In Letras de Hoje, v. 50, n. 2, 2015. Disponível em: <http://revistaseletronicas.pucrs.br/ ojs/index.php/fale/article/view/21339>. Acesso em: 25 jun. 2018. DOI: http://dx.doi. org/10.15448/1984-7726.2015.2.21339

PIRES, Maria Isabel Edom. Em viagem: sobre outras paisagens e movimentos no romance contemporâneo. Estudos de Literatura Brasileira Contemporânea, n. 44 p. 389-403, 2014

PRATT, Mary Louize. Criticism in the Contact Zone: Decentering Community and Nation In: BELL, Steven M.; LE MAY, Albert; ORR, Leonard (Ed.). Critical Theory, Cultural Politics and Latin American Narratives. Notre Dame: University of Notre Dame Press, 1993. p. 83-102.

VIDAL, Paloma. E a origem sempre se perde. In: CHIARELLI, Stefania; OLIVEIRA NETO, Godofredo de. Falando com estranhos: o estrangeiro e a literatura brasileira. Rio de Janeiro: 7Letras, 2016. p. 33-47.

Recebido em 30/06/2018

Aceito em 09/08/2018. 